\title{
The Status of HIV/AIDS Management Strategies in Correctional Settings in Kenya: A Case Study of Lang'ata Women and Kamiti Maximum Prisons
}

\author{
Lucy Wanjiku Musili*, Paul N. Mbatia \\ Department of Sociology, University of Nairobi, Kenya
}

Copyright $\bigcirc 2016$ by authors, all rights reserved. Authors agree that this article remains permanently open access under the terms of the Creative Commons Attribution License 4.0 International License

\begin{abstract}
The study examines how the transmission of HIV/AIDS is mitigated by Kenya Prison Service and is guided by four objectives: (a) To measure the perception of Kenyan prisoners on the scourge of HIV/AIDS in prisons; (b) To assess the capacity of Kenya Prison Service in the prevention, control and management of HIV/AIDS in Kenyan prisons; (c) To identify the common practices of managing HIV/AIDS in Kenyan prisons and (d) To evaluate the efficacy of HIV/AIDS management in Kenyan prisons. A survey research of 142 inmates was conducted in 2012/2013. Of these, 98 (69\%) were males from Kamiti and 44 (31\%) were females from Lang'ata prison. The findings of the study show that, a) More than half 79 (56\%) of the total sample in the prisons studied self-reported being infected with HIV b) the reported prevalence of HIV/AIDS is higher among the male respondents as opposed to their female counterparts and c) mean duration of imprisonment was 6 years 2 months. This is not surprising noting that the study was carried out in maximum security prisons where long term inmates are incarcerated. This implies inmates were more knowledgeable about HIV/AIDS. The main obstacles to effective implementation of HIV management programs in Kenyan prisons include a) high prevalence of HIV by inmates; b) lack of clear and proper mechanism of identifying the HIV-positive inmates; c) congestion in prisons; d) poor access to health care services; e) inadequate knowledge about HIV; and f) lack of elaborate discharge planning programs.
\end{abstract}

\section{Keywords HIV/AIDS, Prisons, Kenya}

\section{Background}

In 2014, 36.9 million people were living with HIV/AIDS, 15.8 million people were accessing treatment, around 2 million people were newly infected with HIV/AIDS and 1.2 million people died of HIV/AIDS related illnesses (UNAIDS $^{[1]}, 2015: 3$ ). There were an estimated 34\% fewer
HIV/AIDS related deaths in sub-Saharan Africa in 2014 than in the year 2000. The rates of HIV infection among prisoners in many countries are significantly higher than those in the general population (Wamsley ${ }^{[2]}$, 2008:2). There are approximately nine million men, women and children held in penal institutions around the world with annual turnover of 30 million (Muntingh ${ }^{[3]}, 2007: 1$ ). Africa has an estimated prison population of close to 900,000 while Kenya has an estimated prison population of 50,000 inmates held in 107 prisons (Pris/25/1/Stats/Vol $13^{[4]}$ ).

\section{Problem Statement}

Overall purpose of the study is to inform the discourse of HIV/AIDS management on problematic of implementing mitigation measures to control HIV/AIDS in a prison set up.

Indeed, prison population is susceptible to infectious diseases through exposure to blood and other bodily fluids, drug injection, poor health care, prison overcrowding, demographics, security issues, lack of community support for rehabilitation programs, and high-risk behaviors (Simooya ${ }^{[5]}, 2010$ ). The spread of infectious diseases, such as HIV/AIDS and other sexually transmitted diseases and tuberculosis result largely from needle-sharing, drug use, consensual and non-consensual sex among prisoners (Guillemette ${ }^{[6]}$, 2003). However, few studies have been carried out among prison samples regarding HIV/AIDS infections, prevention and its management. This is due to difficulties in accessing prisons by researchers focusing on prison inmates. This study therefore endeavoured to overcome all the bureaucratic hurdles and to penetrate Kenyan prisons to find out the status of HIV/AIDS and how it is managed.

\section{Research Methodology}

The study focused on the status of HIV/AIDS 
management strategies in correctional settings in Kenya. Owing to the nature of this study, the researchers largely adopted quantitative approach which was supplemented by qualitative approach. The use of the two research methods allowed the researcher to build on the strengths of each method and minimized their weaknesses. Weaknesses of quantitative method, like failure to provide information about the context of the situation, inability to control the environment and pre-determined outcomes was compensated by in-depth interaction with the research participants during interviews, learning about the context, and uncovering new research themes. The researchers used an interview schedule to obtain information from each of the 142 inmates covered. Technically, a standardized questionnaire was used by researchers to conduct face to face interviews with the inmates. The interviews generated quantitative data to convey knowledge, attitude and practice on HIV/AIDS management in Kenyan prisons. To fully understand the prison environment, well selected key informants were covered. The researchers conducted in-depth interviews with the key informants that included: 5 informed officers and inmates from Lang'ata women maximum prison and 7 officers and inmates from Kamiti maximum prison. In addition, 4 policy makers from Ministry of Health and prison department headquarters were also interviewed.

\subsection{Sampling Design of the Study}

Langata women and Kamiti main prisons within Nairobi were selected purposively since they hold long-term convicted inmates targeted by the study. A total of 142 long-term convicted inmates were obtained from the total 643 long-term convicted prisoners. Out of the total sample, 63 of the inmates were general (those who are not infected with HIV/AIDS) and 79 were those infected with HIV/AIDS. General inmates were selected from the two identified prisons through simple random sampling. More specifically, the researchers used simple random sampling technique (rotary technique) to select inmates from two sampling frames - of 102 long-term convicted inmates from Langata women prison and 543 from Kamiti maximum prison provided by the Kenya Prison Service. However, not every inmate picked participated in the study since some opted not to be interviewed/covered by the study. Simple random sampling technique was preferred because it gave equal chance for each member of the group to participate in the study.

In selecting HIV/AIDS positive inmates, snowball sampling technique was adopted. The prison officers in charge of VCT from the selected prisons purposively identified inmates who were in charge of HIV/AIDS support group. The members of the latter group had declared their positive (HIV/AIDS) status and were willing to participate in the study. Using those who had self-declared their positive HIV/AIDS status, the researchers traced the first respondent and interviewed him/her. After the interview, each respondent was requested to help the research team identify another inmate who had also self-declared his/her positive HID/AIDS status. This continued until a sample of 79 HIV-positive inmates was obtained from the two selected prisons. Key informants were selected using the purposive sampling technique. The researchers relied on their own personal judgment to select these respondents, assuming that they held the expertise views on HIV in prisons and were able and willing to share this knowledge. Indeed, a sample of 16 key informants was obtained. These key informants were observant and reflective members of the prison community and Ministry of Health.

\subsection{Role of the Researchers}

This study was carried out in prison that is very difficult to penetrate. Prisons are closed institutions with tight security measures. Therefore the researcher required a research permit from the prisons department that took 3 months awaiting the decision from the prison training committee. During data collection, officer in charge of security referred the researcher to the welfare department that later assigned her an officer to take her through the process. In the study, the researcher targeted both general inmates and those infected with the HIV Virus. The study targeted long-term convicted inmates who are mostly capital offenders from Kamiti and Lang'ata maximum prisons. In Kamiti maximum prison, these inmates are considered a security threat to anyone who comes in contact with them especially female visitors. The prison policy clearly indicates that any visitor coming in contact with inmates including researchers must be assigned officers to guard them throughout their stay in prison. Therefore, researchers were assigned a prison officer who was also in charge of Voluntary Counseling and Testing (VCT) centre in Kamiti prison to accompany and assist the researchers throughout the data collection period. However, since targeted data was sensitive and highly confidential, the presence of a prison officer in the room could have compromised validity. To safeguard the validity of data collected, the researcher requested the officer to stay next to the door while she interviewed each inmate at the right hand corner of the room. The researcher also used low tone and ensured that the officer did not follow the conversation with the interviewee.

\subsection{Primary and Secondary Data Collected}

Primary data was gathered directly from individual inmates (Key respondents) from the selected prisons and key informants, by use of interview schedule and interview guide, respectively. Observational data involved noting and recording of events and behaviors of inmates that facilitated the transmission and spread of HIV/AIDS in Kenyan prisons by use of observation checklist. The researcher observed structures like VCT centers, clinics, laboratories, counseling rooms, dispensary, human resource like health workers among others. Secondary data was obtained from prisons 
records, local and international published and unpublished works, journals from public and private organizations, periodicals, books and the internet and existing literature on HIV in prisons.

\subsection{Data Analysis}

The study employed both quantitative and qualitative procedures of data analysis. Quantitative data received from 142 inmates through was cleaned, coded, entered into a computer and analyzed using frequencies, percentages, means and standard deviation. In addition, descriptive statistics drawn from the Statistical Package for Social Scientists (SPSS) were applied including cross tabulation. Data was edited for completeness and consistency before analysis. For qualitative data, the researcher read through the transcripts and jotted down comments and grouped data into various themes. Preliminary codes were examined for overlap and redundancy while collapsing similar codes.

\section{Ethical Considerations}

Ethical concerns are considered when conducting survey research that involves human subjects (Patton ${ }^{[7]}, 2000: 404$ ). The key guidelines deal with voluntary participation, no harm to respondents, anonymity and confidentiality. The study endeavored to establish the status of HIV/AIDS management strategies in correctional settings in Kenya, which is a sensitive issue due to the stigma and discrimination associated with an HIV/AIDS positive status. Ethical considerations were addressed throughout in all stages of this study, including the design, data collection, data analysis, data reporting, and writing. In the study, we sought permission from the prisons and university authorities before going out to the field. While in the prisons, we sought the consent of the respondents and participants before any interview. We also sought consent from the research respondents before conducting the interviews, and explained candidly to each of them the purpose of the research. Inmates that refused to be interviewed from Lang'ata and Kamiti prisons were allowed to leave the interview room while those interested were interviewed by the researchers. In conducting interviews, confidentiality was assured by withholding and concealing the identity of the research subjects and by using pseudonyms throughout the process of investigation. Some inmates had raised concern that the researcher might share their views with prison officers. The researchers assured each inmate of utmost confidentiality and that there was no name mentioning of those who participated in the study even while presenting the final report.

\section{Results and Discussions}

\subsection{Social and Demographic Characteristics}

Age is a key variable in explaining the nature of prison population. Generally, for both sexes, those aged 26-35 years dominated the prisons studied, as they constituted about half $63(44 \%)$ of the respondents interviewed. Of these, $37(59 \%)$ were males as compared to $26(41 \%)$ female respondents. Conversely, those reported to be aged below $25 \mathrm{yrs}$. were the least $11(8 \%)$. Of these, $7(64 \%)$ were females as compared to $4(36 \%)$ male respondents. Apparently, the mean age of inmates was $28.1 \mathrm{yrs}$. This age structure is not unique in that Kenya's population has a very young age structure $\left(\mathrm{KNBS}^{[8]}\right.$, 2009). These study findings concur with those in a study by LVCT et al. ${ }^{[9]}$, (2008:3), on sexual health and HIV/AIDS knowledge, practice and prevalence among male inmates in Kenyan prisons that revealed the mean age of inmates to be 31.1 yrs. This suggests that Kenyan prison population is dominated by the young and energetic category of population. This is sexually active age and may engage in risky sexual behaviours as a result of incarceration that may expose them to HIV infections.

Sex is an important variable in studying human behaviour. Of the sample of 142 respondents, $98(69 \%)$ were males and $44(31 \%)$ were females. This clearly indicated that there were more male inmates in Kamiti than female respondents in Lang'ata women prison that met the study criteria. Generally, male populations usually dominate prisons (Coyle $\left.{ }^{[10]}, 2002\right)$. The inclusion of both sexes enabled the study to compare HIV/AIDS management among the male and female prisons in Kenya.

Marital status is a key variable in explaining the attributes of population in Kenyan prisons. As expected in many African communities, nearly half $70(49 \%)$ of the total sample reported to have been married by the time of interview in the prisons studied. Of these, $58(83 \%)$ were male as compared to $12(17 \%)$ who were female respondents. Only about a third 46 (32\%) reported to have been single and a meager (9\%) who reported to be divorced. Thus, inmates in the selected prison are expected to uphold morality with less risky behaviours like prison fights and sex that may expose them to HIV/AIDS infections as expected of people in family and marital unions.

Education is a key determinant of one's social economic status. There was low $6(4 \%)$ level of illiteracy as indicated by those who had no education at all (none) in the prisons studied; male and female respondents were equally represented. The study also affirms that the majority 58 (41\%) of the respondents had secondary level of education. Of these, $37(64 \%)$ were male as compared to $21(36 \%)$ who were females respondents. The study's sample therefore included a substantive per cent with secondary level of education. These study findings could be attributed to the fact that in Kenya, girls receive less education than boys (Ondieki ${ }^{[11]}$, 2012:1). High number of literate inmates in the prisons studied could be attributed to the fact that in Kenya, there is a high $(62 \%)$ national adult literacy rate (KNBS $\left.{ }^{[12]}, 2006\right)$. This implies that due to higher level of education, inmates would be able to protect themselves from HIV.

Religion is a powerful tool in understanding social and 
demographic characteristics of respondents. Given that Kenya is largely a Christian country, it was not surprising to note that the majority 126 (89\%) of respondents interviewed reported to be Christians (protestants and Catholics). Of these, majority $83(66 \%)$ were male respondents as compared to 43 (34\%) who were females. The study findings concur with those of the Kenya Demographic Health Survey of 2009 by Kenya National Bureau of Statistics (KNBS ${ }^{[13]}$, 2010 ) that revealed that approximately $89 \%$ of the Kenyan population is Christian, including 63\% protestant and 26\% Catholic. This clearly indicates that Christianity was the most practiced religion in the prisons studied, as reflected in the general population. Christianity is associated with morality. It is therefore expected that if prisoners upheld strong Christian values, they would embrace morality and avoid risky behaviours such as drug injections and homosexuality. This way, religion could help to reduce the spread of HIV/AIDS in the prisons.

\subsection{The HIV/AIDS Status of Inmates}

Inmates' HIV status is crucial in determining the status of HIV management strategies in the selected prisons in Kenya. More than half $79(56 \%)$ of the total sample in the prisons studied self-reported being infected with HIV. Of these, 54 $(68 \%)$ were males and $25(32 \%)$ were female respondents. Another $41(29 \%)$ of the total sample reported not being infected with HIV. Of these, $28(68 \%)$ were males as compared to $13(32 \%)$ female respondents. Further, reports indicate that $22(16 \%)$ of the total sample reported that they did not know their HIV status. Of these, $16(73 \%)$ were males and $6(28 \%)$ female respondents. This is a clear indication that the reported prevalence of HIV/AIDS is higher among the male respondents as opposed to their female counterparts in the prisons studied. This could be attributed to higher risky behaviour like prison fights, sex and rape in male as compared to female prisons studied. Knowing HIV/AIDS status by inmates would make them more responsible in the fight against HIV/AIDS.

\subsection{Type of Crime}

Type of crime determines how long one would stay in prison. About a third $(35 \%)$ of the sample, reported to have been in prison for being charged with robbery with violence. Of these, 46 (94\%) were male respondents as compared to 3 $(6 \%)$ female respondents. This is not surprising noting that the study was carried out in maximum security prisons. However, females had committed less serious crimes as compared to their male counterparts. This could be attributed to financial responsibility bestowed on males as compared to females in the society that prompted them to engage in crime as they fend for their families. Goffman believes that when someone is stocked with a deviant label his/her fate is changed (Bilton ${ }^{[14]}, 1988$ ). These findings however differ with those in a study on youth and crime by the UN Habitat ${ }^{[15]},(2003)$ in Nairobi that found the major grounds on which young people are charged is theft, assault, drug possession, mugging, and manslaughter. More serious crime like the sample interviewed means long stay in prison and that long term inmates may be more conversant with HIV prevention measures before exiting prison walls.

\subsection{Duration of Imprisonment}

Duration of imprisonment is an important factor in understanding the seriousness of crime committed by inmates. It is the period an offender spends in prison for committing a certain criminal offence. In the study, respondents were requested to reveal how long they had been jailed for the offence committed and data cross-tabulated with sex to compare who between male and female were jailed for longer periods of time. Around half $80(56 \%)$ of the entire sample were jailed above twelve years. Of these, 72 $(80 \%)$ were male respondents and $8(20 \%)$ were female respondents. The mean duration of imprisonment was 6 years 2 months. This is not surprising noting that the study was carried out in maximum security prisons where long term inmates are incarcerated. This implies that inmates were more likely to be knowledgeable about HIV/AIDS since being jailed for longer period would predispose them to more information on HIV/AIDS in a controlled setting. Moreover, they would also become more acquainted with HIV/AIDS management strategies in the selected prisons.

\subsection{Length of Stay in Prison}

Length of stay in Prison refers to the actual period an inmate has spent in a specific prison. It is relevant in determining the inmates' understanding of the prison environment and how the prison department operates. The study targeted respondents who had stayed in prison six months and above and data cross-tabulated with sex to compare who among male and female respondents had stayed longer in the prisons studied. Indeed, over two thirds $92(85 \%)$ of the total sample reported to have stayed in prison above 3 years. Of these, 72 (78\%) were male respondents as compared to $20(22 \%)$ females. More specifically, $25(18 \%)$ of the total sample reported to have stayed in prison above 12 years. The mean duration respondents had spent in prisons was 4 years 4 months. This could be attributed to the shorter sentences served by female inmates due to less serious offences as opposed to their male counterparts. This suggests that respondents had stayed in prisons studied long enough to be familiar with the general operational issues of those prisons including how the Kenya prison service managed its affairs including HIV/AIDS programs. Long stay in prison may translate to more prevention measures being understood and practiced by inmates thus a reduction in HIV/AIDs infections.

\subsection{Prison Visit}

Prison visit is essential to the well-being and progress of 
the incarcerated individuals. In the study, respondents were requested to indicate whether or not visitors were allowed to visit them in prison. Visitation data was cross-tabulated by sex to allow comparison. Over three quarters 127 (89\%) of the total sample reported that they had been visited by the time of interview. Of these, $90(71 \%)$ were males as compared to $37(29 \%)$ who were female respondents. It was also found that $15(11 \%)$ reported that they had not been visited. Of these, $8(53 \%)$ were males and $7(47 \%)$ were female respondents. More prison visits could be a clear indication that Kenya prison service has embraced prison reforms tailored towards the overall well-being of all inmates which is essential in managing HIV/AIDS the prisons studied. More male inmates visited than females could be attributable to weaker family ties that exist between female inmates and their families once they are imprisoned as compared to their male inmates. More visitations may translate to less stress among inmates as those who visit support and comfort inmates.

\subsection{Knowledge of HIV/AIDS by Inmates}

Knowledge of the prisoners on HIV/AIDS is a key determinant in the management of HIV/AIDS in prisons. It informs the attitude and behaviour of the prisoners when it comes to sexual issues. In the study, respondents were requested to reveal their understanding about HIV/AIDS and data cross tabulated with sex to compare who between males and females understood HIV more. Majority 79 (56\%) of the total sample understood what HIV/AIDS is (Human Immunodeficiency Virus). Of these, 57 (72\%) were male as compared to $22(28 \%)$ who were female respondents. On the other extreme, only $2(1 \%)$ of the total sample reported to have no idea what HIV is. Of these, $1(50 \%)$ were male and $1(50 \%)$ female respondent. Data further show that $14(10 \%)$ had 'some' (A virus that causes AIDS) understanding about HIV/AIDS. Of these, $13(93 \%)$ were males as compared to 1 (7\%) who were female respondents. This implies that more HIV/AIDS prevention and control efforts are channeled towards change in attitude to impart change in behaviour of inmates in the prisons studied. The study findings however differ with Rotily ${ }^{[16]}$, (1999:57) whose study on HIV knowledge by inmates revealed that the average scores of knowledge and tolerance towards HIV infected people in France were lower among inmates. Being knowledgeable means that being able to know what is expected in HIV/AIDS prevention and management as well as avoiding risky behaviours hence a reduction in HIV/AIDS transmission and infections. This is a clear indication that inmates in the prisons studied were knowledgeable about HIV. It could therefore be assumed that they prevented themselves from getting infected by the virus.

\subsection{Exposure to HIV/AIDS Information by Inmates}

HIV/AIDS exposure is an essential part of HIV/AIDS prevention in prisons. In this study, respondents were requested to reveal whether or not they were exposed to HIV/AIDS information. Attempts were also made to cross-tabulate HIV/AIDS exposure between male and female to compare how they fared in regard to HIV/AIDS information. It is confirmed that inmates were exposed to HIV information, mainly on mode of transmission and prevention. This is carried out through awareness campaigns by prison staff, care givers and other fellow inmates and through mass media and at the VCT centres. Indeed, around three quarters 127 (89\%) of the total sample reported having being exposed to HIV/AIDS information. Of these, 87 (69\%) were male respondents as compared to $40(32 \%)$ who were females. On the other extreme, only a meager $15(11 \%)$ reported not being exposed to HIV/AIDS information. Of these, 11 (73\%) were males and 4 (27\%) female respondents. The study findings concur with the findings by NASCOP ${ }^{[17]}$, (2012:15) on the MARPS surveillance report that reported high knowledge level on the general awareness of HIV/AIDS transmission and prevention among inmates in Kenyan prisons. In this study, inmates were exposed to HIV/AIDS information. This implies that after knowing what HIV/AIDS is, its cost and implications, inmates would be expected to change their behavior appropriately and protect against infection.

\subsection{Awareness of HIV/AIDS Activities}

Creating HIV/AIDS awareness helps in preventing HIV/AIDS among inmates. In the study, respondents were requested to reveal what awareness activities were provided to them in preventing HIV/AIDS in the prisons studied. Both male and female were cross-tabulated to compare how campaigns fared in male and female prisons studied. Over half $75(53 \%)$ of the total sample reported that VCT was the most common awareness activity carried out against HIV/AIDS in the prisons studied. Of these, $51(68 \%)$ were male respondents as compared to $24(32 \%)$ who were female respondents. Abstinence was the least 5 (14\%) reported activity against HIV/AIDS by inmates. This clearly implies that awareness on HIV services in the prisons studied is a major factor in accessing and using the HIV preventing services as indicated by Rotily et al., (1999). This is because proper understanding about HIV removes unreasonable fears and stigma about the disease (Duh $\left.{ }^{[18]}, 1991: 24\right)$. These study findings concur with those in a report by the United Nations focusing on Stabilization Mission for Kananga central prison. The latter was an outreach campaign on public awareness about sexually transmittable diseases and HIV in the Democratic Republic of Congo (MONUSCO ${ }^{[19]}, 2012$ ). This yielded positive results on HIV/AIDS prevention (Ibid).

\section{Conclusions}

This study attempted to establish the status of HIV/AIDS management strategies in correctional settings in Kenya. Overall, the study findings suggests that majority of prison 
inmates in Kenya are youths who are generally regarded as sexually active and who carry a higher risk of HIV/AIDS infection. On the other hand, majority of them are reasonably well educated and may be able to understand HIV/AIDS prevention strategies and implement them at ease in the fight against HIV/AIDS. Men tend to dominate in Kenyan prisons and hence may have a higher risk behaviours like- drug injections and homosexuality. Reasonable levels of education could make it easier for learning and implementing HIV/AIDS prevention strategies in Kenyan prisons.

The main obstacles to effective implementation of HIV management programs in Kenyan prisons appear to be high prevalence of HIV/AIDS by inmates, lack of clear and proper mechanism of identifying the HIV/AIDS-positive inmates, prisons congestion, poor access to health care services, inadequate knowledge about HIV/AIDS, inadequately exposure to HIV/AIDS information by inmates, poor facilitation of continuity of HIV programs in the transition from prison to community as well as lack of elaborate post-release or discharge planning program to sick and terminally ill patients.

\section{REFERENCES}

[1] UNAIDS 2015. World AIDS Day: AIDS by Numbers. Geneva, Switzerland: UNAIDS

[2] Wamsley, Roy. 2008. World prison population list. $\left(8^{\text {th }}\right.$ Edition). London: International Centre for Prison Studies

[3] Muntingh, Lukas. 2007. Responses to combating HIV/AIDS in prisons through consideration of the WHO guidelines: Establishing a common approach. Unpublished paper presented at CESCA Conference. Switzerland.

[4] Pris/25/1/Stats/Vol 13.

[5] Simooya, Oscar. 2010. "Infections in Prison in low and Middle Income Countries: Prevalence and Prevention strategies". Open Infectious Diseases Journal 4: 33-7.

[6] Guillemette, Sean (2003). "The silent killer doing time".
[7] Patton, Michael, Quinn. 2000. Qualitative evaluation and research methods ( $3^{\text {rd }}$ Edition). London: SAGE

[8] Kenya National Bureau of Statistics (KNBS). 2009. National housing and population census report. Nairobi: Government Printer.

[9] Liverpool Voluntary Counseling and Testing (LVCT), Kenya Prisons service (KPS) and African Medical and Research

[10] Coyle 2002 Coyle, Andrew. 2002. A human right approach to prison management: Handbook for prison staff. London: International Centre for Prison studies.

[11] Ondieki, Lydiah, Gesare. 2012. A study of parental involvement in preschoolers' academic work in Dandora educational zone of Nairobi county, Unpublished Masters project submitted at the University of Nairobi: Kenya

[12] Kenya National Bureau of Statistics (KNBS) and Ministry of Planning and National Development (MPND). 2006. Kenya Integrated Household Budget Survey (KIHBS) 2005-2006. Nairobi: Government Printer.

[13] Kenya National Bureau of Statistics (KNBS) and ICF Macro. 2010. Kenya demographic and health survey 2008-09. Calverton, Maryland: KNBS and ICF Macro.

[14] Bilton, Tony. 1988. Introductory Sociology. (2 ${ }^{\text {nd }}$ Edition). London: Macmillan.

[15] UN-Habitat. 2003. Global report on human settlement: Facing the challenge of slum. Nairobi: UN-Habitat.

[16] Rotily Michel; Galinier-Pujol, A. and Moatti J.P. et al. 1999. Knowledge, beliefs and attitudes of inmates towards AIDS and HIV infection: A survey in Marseille penitentiary Centre, 47, (3): 229-238.

[17] National AIDS and STD Control Program (NASCOP) and Ministry of Health (MoH). 2012. MARPS surveillance report: What about the burden of HIV/AIDS and associated risk factors for MARPS'. Nairobi, Kenya: NASCOP.

[18] Duh, Samuel. 1991. Blacks and AIDS. Newbury Park, CA: Sage Publications.

[19] Corrections of the United Nations Stabilization Mission in DRC (MONUSCO), Provincial Sanitation Department in Kansai Occidental institutions. 2012. Campaigns against HIV and STD infection in Kananga prison. MONUSCO. 